\title{
Localization of the English Public Speaking Course in China's EFL Curriculum
}

\author{
Jiangbo Wan ${ }^{1}$ \\ ${ }^{1}$ College English Center, Fudan University, Shanghai, China \\ Correspondence: Jiangbo Wan, College English Center, Fudan University, Shanghai, China. E-mail: \\ jbwan@fudan.edu.cn
}

Received: September 23, 2012 Accepted: October 23, 2012 Online Published: December 31, 2012

doi:10.5539/ass.v9n1p94

URL: http://dx.doi.org/10.5539/ass.v9n1p94

\begin{abstract}
English Public Speaking has been introduced into China's tertiary curriculum only very recently. Although similar to its Western counterpart in many ways, a number of crucial elements of this course have yet to be localized. Apart from being a communication course, it is intrinsically an EFL course which builds upon and extends other courses in the EFL curriculum. Accordingly, the teaching objectives and content should be localized and adapted to China's status quo and students' need. Then this article moves on suggesting some localized methods to instruct small classes as well as large classes. It suggests that the formative assessment be used to best elicit students' reflection and progress and that a combined measure of quantitative-and-qualitative assessment, teacher-and-student assessment be used to achieve the best backwash. Last but not least, the article also introduces the potential research areas that can be explored in the years to come.
\end{abstract}

Keywords: English Public Speaking course, localization, EFL curriculum, teaching objectives, methods of instruction, formative assessment

\section{Introduction}

The course of English Public Speaking has entered the arena of China's tertiary education only very recently. Many teaching practitioners have been using textbooks or copying directly the teaching objectives, the chapters, methods of instruction, etc., from its equivalent course of western countries, only to find that it does not perfectly meet the requirements of China's tertiary curriculum or the demands of our students. After teaching and researching in this field for 5 years, the author calls on localizing the course and reorienting its teaching objectives, course design and assessment.

\section{Historical Overview}

It was recorded in year 1924's "Curriculum Guidance" of the English Department, Peking University, that Professor Yang Yinqing taught "Debating" and "Public Speaking" to English majors (Xu, 1989, p. 52), but these courses vanished as fast as they appeared - ever since then the English Public Speaking course has been absent from China's EFL curriculum for over 70 years.

In China's current EFL curriculum, the English Public Speaking course is a new arrival compared to most other courses. As far as this study has found, the first English Public Speaking course in tertiary education after the founding of the People's Republic of China was offered in 1991 by Su Xunwu in Heilongjiang University (Su, 1997), and from 1991 to 1999 there were only two more universities in China mainland offering this course, namely Beijing International Studies University and Beijing Foreign Studies University (Wang, 2009). The number grew very slowly between 2000 and 2005. According to Ren Wen, there were less than 20 universities offering the course during this period, but by year 2011, the number rockets to over 200 (Note 1). See Figure 1. 


\section{The Increasing Number of Universities Offering the English}

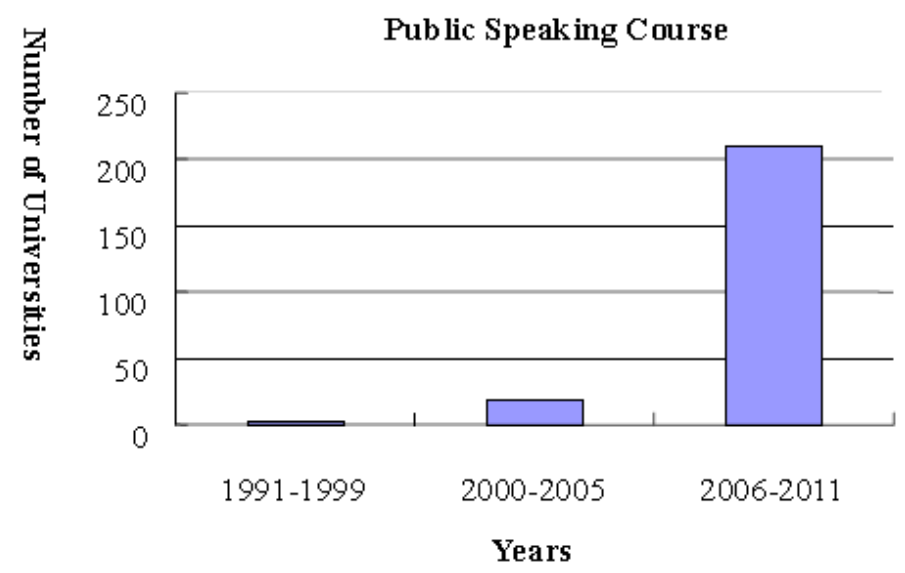

Figure 1. The increasing number of universities offering the English Public Speaking course

The causes of this sharp increase are multifold. First, the accelerative trend of globalization and the booming of China's economy in the past decade have pushed China to the center of the world stage, and more urgently than ever China needs to communicate with the rest of the world. Known as the official world language, the English language is taught in China as a most important foreign language, and cultivating students' English communication skills has been prioritized in the 2007 College English Curriculum Requirements (CECR) issued by China's Ministry of Education. (Note 2).

Second, the growing rate of English Public Speaking courses in China's tertiary education is related to the growing popularity of English public speaking competitions in the past 16 years. Among mushrooming English public speaking competitions at collegiate, provincial, regional and national levels, two nationwide competitions - the $21^{\text {st }}$ Century Cup National English Public Speaking Competition initiated in 1996 and CCTV Cup National English Public Speaking Competition (now known as FLTRP Cup National English Public Speaking Competition) initiated in 2000 - have played a leading role and exerted a powerful influence on China's EFL curriculum, triggering researching and teaching interest of English Public Speaking in the TESOL circle (Lü, 2009; Wan, 2011; Wu, 2009), because before mid-1990s, public speaking, even in Chinese, was almost a virgin land to modern Chinese people and was not encouraged as it is today. Therefore competitive English public speaking, although artificial in nature, was quite a phenomenon when it first landed on China's soil. Those competitions have created chances for contestants to openly voice their personal opinions, highlighted individuality, changed many people's lives, and, last but not least, inspired the English public speaking coaches of different universities and colleges - the author is one of the hundreds - to probe into the necessity of opening up English Public Speaking as a course to Chinese students.

Third, students are in great need of English public speaking skills as a tool for their future career success as well as for individual self-actualization. According to a 2002 survey of 500 business administrative personnel and business professionals in China, speaking and listening are ranked as the most important English skills required in their jobs, above reading, writing, and translating (Pang, Zhou \& Fu, 2002). Many reports have revealed that there is a loud demand for English public speaking skills from Chinese college students (Wan, 2011; Wang, 2009; Zhang, 2009). They believe that the teaching of these skills can help build their self-confidence and communicative awareness, offer them opportunities to express their thoughts in English, improve their critical thinking skills, and enhance their abilities to use English in a comprehensive way (Zhang, 2009, p. 130).

Today in China, with a lot more platforms for young people to showcase their talent and voice their opinions, the popularity of competitive English public speaking with English-learners is gradually sliding downhill compared with 10 years ago. However, the English Public Speaking course - the lucky byproduct of it - has just found its permanent place in China's tertiary education curriculum.

\section{Localization of the English Public Speaking Course}

\subsection{Problems to Address}

Over years of teaching and researching in this field, the author has found that some critical problems have to be addressed before the English Public Speaking course can develop healthily and durably in China in the years to come: 
1) What is the fundamental difference between the Public Speaking course taught in English-speaking countries and the English Public Speaking course in China?

2) How should the course define its teaching objectives?

3) What should be the main content of the course?

4) What are the most desirable methods of instruction?

5) How should teachers evaluate students' performance?

In one word, how should we localize the English Public Speaking course so that it will work best for Chinese students, teachers, the society, and the education cause?

\subsection{The Nature of the Course}

In many universities in China, teachers have adopted original textbooks from Western countries. It goes without saying that most those textbooks are very comprehensive and systematic in their content and very instructive and helpful to their intended audience, but basically they are written against the backdrop of Western culture and are not intended for Chinese EFL learners particularly. When these books are used in China, every now and then complaints are heard from both teachers and students that the textbooks are either inconvenient to use or not instructive enough. On the other hand, the number of local English Public Speaking textbooks is scant, and those on shelves are at best manuals about English public speaking rather than a standard work for the study of public speaking with a systematic body of knowledge and a well-organized plan of trainings. This problem is largely due to the lack of reorientation to the local status quo.

Public speaking is known as "rhetoric" in ancient Greece where the Western civilization was born. Throughout the centuries, rhetorical education has played a significant role in Greek-Roman education and "In (in) classical times, training in rhetoric was part of educating the whole person" (Jamieson, 1988, p. 16). In the United States, for example, Public Speaking is a compulsory course for all undergraduates in most universities and colleges and is usually offered by the department of communications, rhetoric, or performing arts, etc.

In China, however, the English Public Speaking course is usually offered by the Department of Foreign Languages, either to English majors or non-English majors. It has entered the EFL curriculum not primarily because English public speaking skills help cultivate "the whole person", but that we aim to prepare our students better for their future international communication in English, a foreign language which is notably an international working language. Eventually English Public Speaking has found its permanent place in China's tertiary education curriculum at the top of oral English proficiency (see Figure 2).

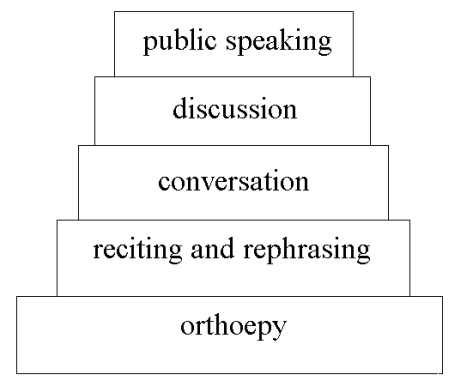

Figure 2. Different phases of oral English proficiency

Source: Shen, 1999, p. 57-60.

In Western countries, public speaking and its research are carried out in a cross-disciplinary perspective which includes communications, rhetoric, psychology, sociology, linguistics, etc. While in China, the English Public Speaking course is basically an EFL course, which "builds upon and extends other courses in the EFL curriculum" (Lucas, 2009, p. 18). Besides those cross-disciplinary studies done in Western countries, the research of English Public Speaking in China also involves TESOL studies, second language acquisition (SLA) studies, pedagogy, cross-cultural studies, etc.

\subsection{The Teaching Objectives and Main Content}

As an EFL course, English Public Speaking gives consideration to both language proficiency and communication skills. The teaching objectives of the course are described to my students as follows:

1) To build your self-confidence and develop your interest in English public speaking; 
2) To develop your ability to write effective English public speeches;

3) To develop your ability to effectively deliver English public speeches;

4) To develop your speaker responsibility;

5) To develop your listener responsibility;

6) To develop your research skills and cooperation skills.

The above objectives are listed in order of importance. The first three objectives start from EFL-related abilities, but they are meantime closely related to psychological techniques, research approaches, and communicative skills. First of all, before, while and after giving a public speech in English, EFL students are usually under double anxiety, ie, public speaking anxiety and foreign language anxiety, which increases the difficulty of overcoming nervousness at the first stage. Therefore, teachers are supposed to make the preliminary speaking tasks manageable and appealing for students to start with. Meanwhile, special psychological techniques can be shared with them to fight nervousness and manage anxiety. The paramount fact about nervousness should be clarified in the very beginning: nervousness, if managed well, can be converted to energy and work to their advantage. On the other hand, during the entire teaching process, students should be given sufficient instructions in language use, including linguistic and rhetorical analysis of classical English speeches, typical sentence patterns in public speeches, correct pronunciation, word choices, grammar, etc. To achieve the first three objectives, instructions should also cover selecting topics, collecting data, narrowing and focusing topics, learning different types of speech (namely, persuasive speeches, informative speeches, and ceremonial speeches - to prepare students for their future work and lives, speeches for academic or special purpose are an important genre for students to learn and practice), supporting ideas with reasoning, organizing message for effective communication, preparing and revising drafts, using language accurately, vividly, and appropriately, learning vocal and nonverbal principles of effective speech delivery, using visual aids effectively, rehearsing, so on and so forth.

The fourth and fifth objectives aim to cultivate students' awareness of their role in a public speaking setting. Speaker responsibility entails commitment to the preparation of a quality speech, employment of critical thinking skills, cross-cultural consciousness, cross-cultural communicative competence, credibility, respect to one's audience and the occasion, etc. However, public speaking is not only about speaking, but also about listening. It is a game between the speaker and audience. There is full of give-and-take during the whole process. The audience is not a passive receptacle, but an active bargainer. People can show their attitude towards a point and respond to questions and challenges posed by the speaker. Listener responsibility entails the ability to take notes, the ability to listen effectively and critically, the ability to synthesize information, the ability to interact with the speaker, etc. The fifth objective of the course is extremely constructive for Chinese students, because in China, we have an age-old tradition of listening attentively without questioning the person who possesses the discourse power. Otherwise, it would be considered rude to the speaker. Yan Hui (Note 3) never said "no" to his master, Confucius, and his obedience and reticence was highly appreciated by the latter and has been considered exemplary by Chinese scholars ever since. However, in an English Public Speaking class, students are encouraged to listen with an open mind to what others have to say.

The last objective, the cultivation of research skills and cooperation skills, is realized through the whole teaching and learning process, including teachers' exemplification and requirements, data-collection, class activities (especially speeches for academic or professional purpose), speaker-audience interaction, etc.

Of all the teaching objectives mentioned above, two emphases deserve our special attention: cross-cultural communicative competence and critical thinking skills in English.

First, as other EFL courses, the English Public Speaking course intrinsically utilizes concepts of culture along with foreign language studies, with an attempt to help students grasp strategies to develop cross-cultural communicative competence. Cross-cultural communicative competence, or intercultural communicative competence, includes understanding the complex relations between language and culture, avoiding ethnocentrism, encouraging reflection on the functions of one's own language and community, and equipping learners to analyze and interpret culture in general. (Byram, 1997 \& 2008; Corbett, 2003) It necessitates the abilities to think, speak, and behave in ways that recognize and respect cultural diversity in cross-cultural situations.

However, in our classrooms, the demographic feature (eg, age, race, and gender) is not as diverse as, say, America. However, the training of their English public speaking skills should target not only at the influence of a single semester, but that of their future career and life. So teachers should awaken students' awareness of cultural 
considerations. Besides those of their own peers sitting in the same classroom, they are also encouraged to envision themselves in a more globalized setting where the English language is used as a working language where they might probably find themselves in the future. They should be motivated to widen the range of their "general knowledge" and "to draw on the resources of different cultures, especially the cultures associated with the foreign language they use in their speech class" (Yin, 2005, p. 55). They should learn to appreciate emotions, metaphors, humor, etc, in a different light. They should learn to understand body languages and non-verbal messages of different cultural backgrounds. They should be shown the general etiquette in a cross-cultural situation and be instructed to do thorough audience analysis and learn about taboos and boundaries in order to communicate across the barriers of culture. Besides, Yin (2005, p. 54) proposes that "public speaking instructors should recognize the important role of mass media in public speaking education", and teaching students to mine "invisible norms and 'truths' about human difference ... can provide the tools for independent thinking and dismantle the seeds of bias". On the other hand, emphasizing their cross-cultural communicative competence does not mean that our students should consider their own culture secondary or inferior. English public speaking in a global context involves both adaptations to the target culture and appropriate use of resources from one's native culture. (Lucas, 2009)

The second emphasis in an English Public Speaking classroom is to help students develop their critical thinking skills in English. The vital spark of public speaking lies in its effective communication, which comes from critical thinking. As you think critically, your eyes will open all the doors to reading, listening, writing, and speaking effectively, and your mind will keep asking questions and looking for answers. The whole process of preparing a speech and delivering it is very much like that of writing a novel. There is a lot of creativity involved in both businesses. While collecting your data, you analyze and evaluate their importance, effectiveness, truthfulness, and credibility. You consider what is most appropriate and effective for your audience and the occasion. As you move along, you design the best structure for your ideas. You brainstorm so that you know where to head for before you grab a pen and sit down. You play with words so that you can see how they fit in your speech and work for your purpose. You polish your punch lines. Just like a novelist, you may want to record every inspiration occurring to you day and night with pen, paper, recorder, and the like ready at any moment. You read your first draft to yourself and your friends, and keep rehearsing, revising, and refining it until you are satisfied. While actually delivering the speech, you observe your audience and adapt your content and delivery to their reaction spontaneously. After the speech, you inquire of your audience their feedback so that you can do better next time. On the other end, the listeners shall listen critically as mentioned earlier so that as a social event a public speech should be judged squarely and properly and never jeopardize the society. It is because of the indispensability of critical thinking in public speaking that we teachers should instruct students through well-defined assignments and well-planned activities to help trigger critical thinking in every step of their preparing, delivering, and listening to a public speech.

\subsection{Methods of Instruction}

There is no universal way of teaching Public Speaking, nor of teaching English Public Speaking in China. Diversity in methodology should be encouraged to cater to different institutions, students, and teachers themselves. Nonetheless, it is acknowledged as a guiding pedagogical principle that "in ideal circumstances, the pedagogical model for public speaking is experiential rather than contemplative, active rather than passive, personal rather than impersonal" (Lucas, 1998, p. 75).

Personally the author has found that a combined methodology of the communicative approach and the multimedia-based approach serves this principle best in my classes of 20 odd non-English-major undergraduates at Fudan University, one of the top comprehensive universities in China.

The communicative approach to the teaching of foreign languages emphasizes interaction as both the means and the ultimate goal of learning a language, which fits very well in the classroom of English Public Speaking, since central to public speaking is communication. As an extension to the role of a "facilitator" (Rogers, 1969), an English Public Speaking teacher adopting the communicative approach also plays the role of an organizer, a diagnostician, a helper, an advisor, a coordinator, as well as a portfolio-keeper, which will be discussed later. In the English Public Speaking classroom, the communicative approach often takes the form of pair and group work requiring cooperation and evaluation between learners, fluency-based activities such as the delivery of an informative speech or a persuasive speech, role-plays in which some students may act as news spokesmen answering questions from their peers or as personnel officers interviewing the applicants to their companies, debates over some controversial issues, or discussions and oral analyses of a model speech.

Besides, the multimedia-based approach is also an important method of instruction in my classes. It is applied 
largely in the following ways:

1) To display model speech clips on the big screen (usually good models such as Martin Luther King's "I Have a Dream", Steve Job's commencement speech at Stanford University (2005), Ronald Reagan's speech addressing the Challenger Seven tragedy, or model speeches given by my previous students, etc);

2) To display visual aids (PPT, pictures, or other files) on the big screen;

3) To video-record students' speeches for later critique;

4) To record students' recitation of classical speeches for them to study and correct their errors in pronunciation, accent, etc.

Speech models have been an important pedagogical tool since the beginning of systematic instruction in public speaking. (Friedrich, 1983) For EFL students in particular, they are reliable resources of exemplary speeches in terms of language, delivery, organization, content, etc. Model speeches can not only be used in class to exemplify how to use language effectively, how to organize ideas, how to deliver a speech, how to incorporate humour into speaking, etc, but also be used after class for students to study and emulate. However, students are warned at the same time that emulating is only one important channel for input. It does not mean they should forget who they are. Just as Buffon once told us, "Le style est l'homme même" (the style is the man himself). We should show students the importance of developing personal manner so that gradually they can develop their own speaking style based on their own character and disposition.

In my classes, students' every delivery of speech is recorded and filed afterwards. The whole load of speech clips serve as the first-hand portfolio of students' learning process. Students are asked to get a copy of their own speech videos for future self-assessment with the guidance of a self-assessment checklist (Figure 3) as shown in the below.

\begin{tabular}{|l|}
\hline a good preparation (data-collecting, audience analysis, brainstorming, topic \\
selection, script-writing, preparing visual-aids, rehearsing, etc) \\
\hline a clear and definite message \\
\hline a logical order of points \\
\hline a dynamic opening that captures audience attention \\
\hline an effective eye-contact \\
\hline a well-paced presentation \\
\hline a well-modulated voice \\
\hline a rapport with audience members \\
\hline fresh, gripping material that holds audience attention \\
\hline a well-practiced speech, acted with spontaneity rather than read or memorized \\
\hline an effective use of humor \\
\hline an effective use of visual aids in presentations \\
\hline an uncontrived genuine closing that touches or motivates audience members \\
\hline a good time-management \\
\hline
\end{tabular}

Figure 3. Self-assessment checklist

This multimedia-based self-assessment process is very constructive for students to realize their own weakness and develop their public speaking skills, helping them to see themselves from a stranger's angle. Here are some excerptions from my students' self-assessments (Note 4):

1) "After having them (video clips) copied into my iPod, I opened them in my laptop with a feeling of extreme tension. ... after viewing my imperfect videos of my speeches, I've known some of my strengths as well as the aspects to improve." (by Jeremy, 5/31/2012).

2) "When I was delivering the speech in class, I thought the effect was not bad, but when I turn to my video, I still find quite a lot of problems in my speech. My topic selection proved good enough, and I had my audience's attention from beginning to end. The lead-in was humorous and effective, and my PPT was clear and brief. ... but the ending was a bit too abrupt. ... I made too many vocal pauses like 'uh, and, you know', etc. ... I looked a bit uneasy, looking too many times at the big screen. ..." (by Phayue, 6/9/2012, translated by the author)

My teaching practice has proved that the use of multimedia kits in English Public Speaking classrooms can enrich class content, enhance intercultural communication, enliven the class atmosphere, simplify complex explanations, and last but not least, help students with their self-study. Admittedly teachers might have massive work to do in preparation for classes, but it is worthwhile considering all the benefits it brings along. 
However, for many universities and colleges in China, my teaching approaches might not work as effective or might be overtaxing for their teachers, because the English Public Speaking classes are usually very large - some are over 40, some even over 80 , or 100 . Quantity matters. It has been recognized in Western countries that the ideal method of teaching public speaking is in small classes ever since the formal study and instruction in public speaking (or, rhetoric) began in Greece during the 5th century BCE. (Lucas, 2009) In the United States, the size of a public speaking class is usually about 20 students, which allows sufficient time for each student to deliver four to five speeches to the class in a semester without compromising teachers' time of lecturing, appraising, or organizing class activities.

So, how to teach 70 students in a single class? I once taught English Public Speaking for one semester to a class of over 60 as a guest instructor to a cohort of senior high school students. I have to admit that it was not as easy as my usual classes in my home university. To my target students I made some adaptation, which can be briefly summarized as follows:

1) Stronger control of class activities (with a very definite requirement of every step for every person);

2) More lecture time;

3) More time for class discussion;

4) More speech assignments in small groups and less to the whole class;

5) Well-chosen representatives to speak to the class.

Although it was not the most successful teaching experience I have ever had, it turned out quite a success judging by the feedback from students and their school. To teach a large class is like to haul tons of logs with a low horsepower tractor, but if you meticulously plan ahead of time, you can still motivate and help the students.

\subsection{Assessment}

Based on the author's observation, there are three general phenomena in the course assessment of English Public Speaking in China's higher educational institutions. Firstly, the common assessing practice tends to rank students than help and motivate them. Secondly, it attaches more importance to the summative assessment than the formative assessment (Note 5). Last, the assessor of students' performance is usually the teacher exclusively.

These phenomena are not conducive to the development of students' public speaking skills, nor to that of the course per se. The causes of such phenomena are complex. For one thing, as aforementioned, the usual size of English Public Speaking classes is too big, especially for the non-English majors. Teachers have to massively reduce the formative assessment and rely on the summative assessment to keep it manageable. For another, many English Public Speaking teachers themselves haven't yet made an in-depth research into the assessment system, and accordingly their methods of assessment tend to be overly simple or inflexible, without much consideration for the positive backwash on students.

As Professor Stephen E. Lucas once said in his paper, "The (the) main focus of the course, however, should be on the skills of preparing and presenting effective speeches." (2009, p. 10) As is known to us all, it takes a comparatively long time to develop one's skills, and what actually happens during that long process is what we teachers are intensely concerned about. On that account, students should be guided well throughout the entire process of speech-making, and a necessary, maybe, vital part of this guidance lies in timely and constructive feedback about their work. If students get instant diagnostic response to their work, they will draw on the helpful feedback and start all over from a higher standpoint the next time.

When students put in effort to speech-making, they want to hear more substantial comments than simply a numeral score as the final assessment for all their efforts. That's probably why they value constructive critique to their speeches, and they deem "these comments as avenues for them to do better in their next speech attempt". (Kaur, 2005) Hence an effective assessment should use both quantitative and qualitative methods. It should be constructive, diagnostic, and formative, rather than unresponsive, simply numeral, and summative. The holistic evaluation of students' performance shall fairly reflect students' growth and their different skills (writing, delivering, communicating, speaking to inform, persuade, or entertain, etc) exhibited throughout different class activities (Note 6). The following table (Figure 4) shows how I evaluate my students in the previous semester: 


\begin{tabular}{|l|l|c|}
\hline & \multicolumn{1}{|c|}{ Task } & Grading \\
\hline 1. & Informative Speech & 20 \\
\hline 2. & Persuasive Speech & 10 \\
\hline 3. & Script Writing & 10 \\
\hline 4. & Recitation of Model Speeches & 10 \\
\hline 5. & $\begin{array}{l}\text { Class Activities } \\
\text { (Peer Work, Group Work, Class Discussion, etc) }\end{array}$ & 20 \\
\hline 6. & $\begin{array}{l}\text { Final Examination } \\
\text { (Speech of Introduction \& Persuasive Speech) }\end{array}$ & 30 \\
\hline
\end{tabular}

Figure 4. Tasks and grading

The second important suggestion about formative assessment is that students be also involved in the process of assessment. They can be assessed not only by their teacher, but also by their peers and by themselves (namely self-assessment as aforementioned). The involvement of students as assessors can be extremely beneficial to them. In this way, they will know better what standards they are supposed to reach, what is good and what is to be avoided while moving along, and what they shall work on if they want to do better next time. It is a decision-making process for students, involving them in recognizing and reacting to their own and others' evaluations of their learning, eliciting their reflections upon their performance, and motivating them to monitor their own learning process better.

In an EFL context especially, it is advisable that English Public Speaking teachers design their own tailor-made evaluation forms to suit their students' need. When students are actually asked to evaluate their own and their peers' work, the teacher needs to do sufficient instructions as to how to judge a speech comprehensively and then explain fully to them the descriptors used in the evaluation form. For instance, the following evaluation form (Figure 5) devised by the author is distributed to students before they are assigned to deliver a persuasive speech. All the evaluation forms will be returned to the speaker as soon as the class is over, although their peers' scoring might not necessarily be taken into final assessment at the end of the semester.

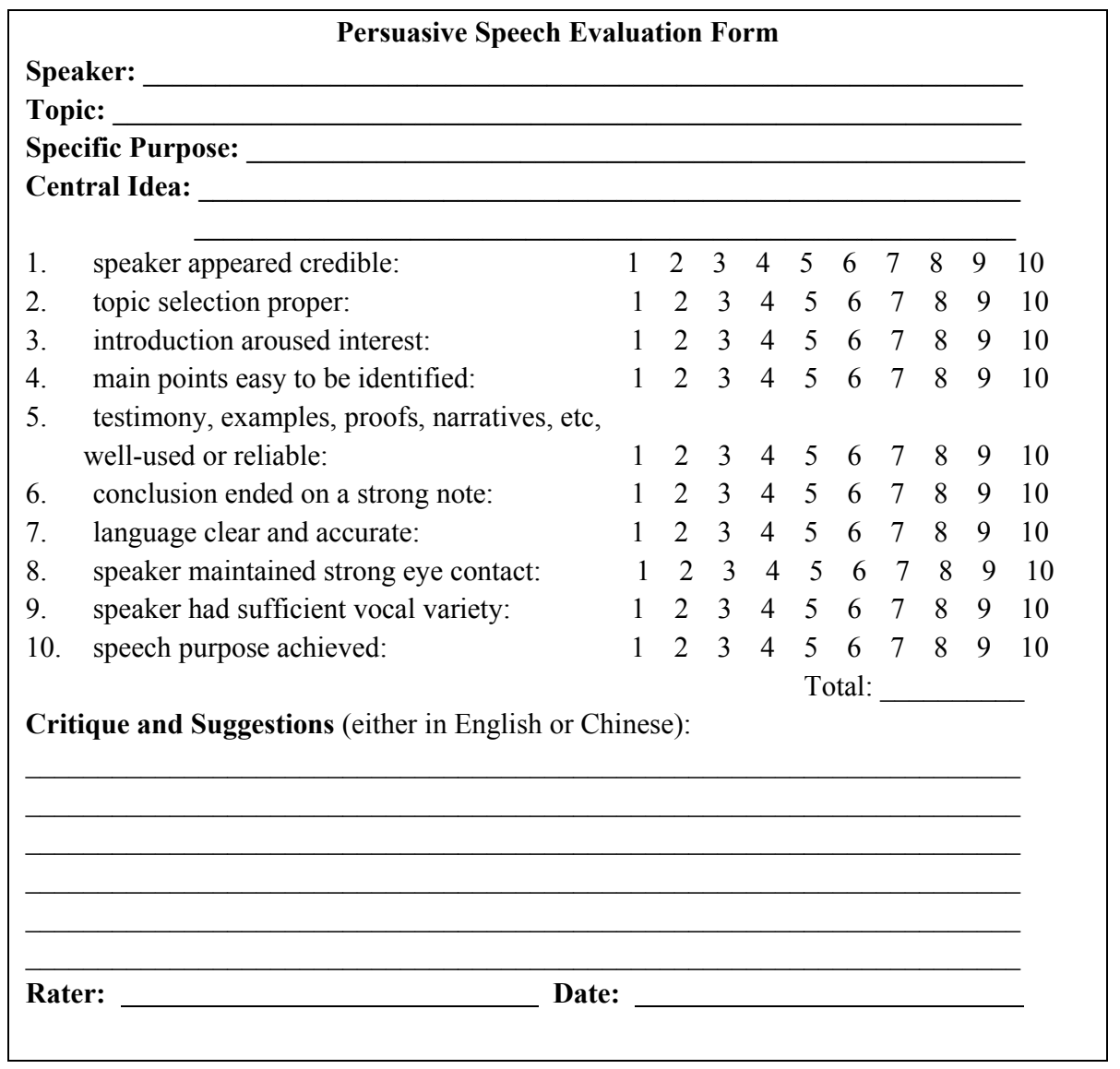

Figure 5.

One additional important fact about the formative assessment in an English Public Speaking class is that it not 
only enables students to monitor their own learning, it also helps the teacher to use the feedback to revise classroom practices. The teacher will find out if students have understood or not, or if they have any difficulty in a particular task or requirement. Based on this knowledge, the teacher may further facilitate students' learning by adapting to their abilities, demand, and problems.

\subsection{Research Areas}

As a new course in China's EFL curriculum, the English Public Speaking course is confronted with a lot of challenges. Though studies on public speaking have a very long history in the Western world, as well as in China, neither can be adopted in China's EFL classrooms if without adapting to the nature and requirements of our EFL curriculum. A lot of new research areas remain untapped ahead of us.

At the Third National Symposium on English Public Speaking (December, 2011) themed "Public Speaking in Progress: On Campus and Beyond", Professor Stephen Lucas gives a visionary key-note speech about the research agenda for China's English Public Speaking practitioners. In his inspiring talk, he proposes that we have at least the following areas to research in the years to come:

1) Foundations of Western Research in Public Speaking (Rhetoric, Study of Famous Orators, etc, Social Science Studies of Speech, Research on Speech Pedagogy);

2) Limiting Factors of Western Foundational Research When Applied to China (Monocultural, Non-EFL);

3) Course Philosophy and Design (Three Challenges for Course Design: English Majors \& Non-majors, Optional \& Compulsory Courses, Large Courses);

4) Teaching Methods and Strategies (Research Options - Teacher Narratives or Micro-accounts of Teaching Strategies; the Communication Teacher);

5) EPS \& Cognate Competencies;

6) EPS \& Specialized Universities;

7) EPS \& Personal Development;

8) Field Research (Public Speaking Anxiety [PSA] \& Foreign Language Anxiety [FLA], Personal Report of Public Speaking Anxiety [PRPSA]);

9) Course Assessment (quantitative and qualitative);

10) EPS and Debate;

11) Speech Analysis;

12) History of EPS in China;

13) Localization of EPS in China.

This is almost an exhaustive list of research tasks for China's EPS circle, serving as solid stepping stones for all EPS practitioners and researchers to further EPS research to a higher level. Other items that the author would feel necessary so far to add to the list are: Writing Local Textbooks, Competitive EPS, EPS for Special/Academic Purposes, and Student Portfolios.

\section{Conclusion}

As a skills development course in EFL curriculum in China, English Public Speaking attaches great importance to students' cognate competences (such as language skills and critical thinking skills), intercultural competencies, and career-related presentation skills, etc. In a measure, its teaching objectives, main content, methods of instruction and assessment have shown different features from Public Speaking in Western countries. Hence the localization of the English Public Speaking course is an emerging but urgent theme for TESOL researchers in China, leaving much to be desired by educators and policymakers in the years to come.

\section{Acknowledgements}

This paper is based on the major research of the English Public Speaking Course (Fudan University), one of the Principal Courses of Shanghai Municipal Education Commission (2010-2012), China.

\section{References}

Ainsworth, L., \& Viegut, D. (2006). Common Formative Assessments. Thousand Oaks, CA: Corwin Press.

Bell, B., \& Cowie, B. (2001). The Characteristics of Formative Assessment in Science Education. Science 
Education, 5, 536-553. http://dx.doi.org/10.1002/sce.1022

Black, P., \& Wiliam, D. (1998). Assessment and classroom Learning. Assessment in Education: Principles, Policy \& Practice, (5), 7-74. http://dx.doi.org/10.1080/0969595980050102

Byram, M. (1997). Teaching and Assessing Intercultural Communicative Competence. Clevedon: Multilingual Matters.

Byram, M. (2008). From Foreign Language Education to Education for Intercultural Citizenship: Essays and Reflections. Clevedon: Multilingual Matters.

Corbett, J. (2003). An Intercultural Approach to English Language Teaching. Clevedon: Multilingual Matters.

Friedrich, G. W. (1983). The Use of Model Speeches. Paper presented at the Annual Meeting of the Speech Communication Association (69th, Washington, DC, November 10-13, 1983).

Green, J. W. (1982). Cultural Awareness in the Human Services. Englewood Cliffs, NJ: Prentice Hall.

Jamieson, K. H. (1988). Eloquence in an Electronic Age: The Transformation of Political Speechmaking. New York: Oxford University Press.

Kaur, S. (2005). Suggestions for Teaching Public Speaking and Evaluating Speeches. The Internet TESL Journal, 6(7). Retrieved from http://iteslj.org/Techniques/Kaur-PublicSpeaking.html

Lucas, S. E. (1998). Teaching public speaking. In A. Vangelisti, J. A. Daly, \& G. Friedrich (Eds.), Teaching Communication: Theory, Research and Methods (2nd ed., pp. 75-84). Hillsdale: Lawrence Erlbaum Associates.

Lucas, S. E. (2009). The Role of Public Speaking in China's English Language Curriculum. In L. Wang, \& P. Li (Eds.), English Public Speaking in Global Context: Challenges and Innovations (pp. 3-24). Beijing: Foreign Language Teaching and Research Press.

Lucas, S. E. (2010). Teaching Public Speaking. FLTRP Workshop Book of "the Workshop on Teaching Public Speaking to College Students" (May 29-30, Nanjing), 72-82.

Lü, X. (2009). A Historical Overview of Public Speaking Traditions and Practices in China and the West. In L. Wang, \& P. Li (Eds.), English Public Speaking in Global Context: Challenges and Innovations (pp. 32-46). Beijing: Foreign Language Teaching and Research Press.

Lynch, E. W., \& Hanson, M. J. (1998). Steps in the right direction: Implications for interventionists. In E. Lynch, \& M. Hanson (Eds.), Developing Cross-cultural Competence: A Guide for Working with Children and Their Families (2nd ed., pp. 483-520). Baltimore, MD: Brookes.

McKay, S. L., \& Bokhorst-Heng, W. D. (2008) International English in Its Sociolinguistic Contexts: Towards a Socially Sensitive EIL Pedagogy. New York: Routledge.

Ministry of Education. (2007). College English Curriculum Requirements. Beijing: Higher Education Press.

Pang, J., Zhou, X., \& Fu, Z. (2002). English for international trade: China enters the WTO. World Englishes, 21(2), 201-216. http://dx.doi.org/10.1111/1467-971X.00242

Rogers, C. (1969). Freedom to Learn. Columbus, OH: Charles E. Merril.

Shen, W. (1999). Five Stages of Oral English Teaching. Journal of Beijing University of Posts and Telecommunications, 3, 57-60.

$\mathrm{Su}$, X. (1997). A Study on Teaching English Public Speaking to English Majors. Foreign Language World, 1, 15-18.

Wan, Jiangbo. (2009). Course Design of the English Public Speaking Course for Non-English Majors. Foreign Language Education in China (Quarterly), 2, 55-61.

Wan, J. (2011). Course Design and Teaching Methodology of the English Public Speaking Course in Tertiary Education. National College English Teaching Workshop (Keynote speech, at Nanchang, Jiangxi Province of China on July 25).

Wang, T. (2009). Developing Public Speaking Course for English Majors. In L. Wang, \& P. Li (Eds.), English Public Speaking in Global Context: Challenges and Innovations (pp. 134-143). Beijing: Foreign Language Teaching and Research Press.

Wu, M. (2009). On Teaching College English Public Speaking Course. In L. Wang, \& P. Li (Eds.), English Public Speaking in Global Context: Challenges and Innovations (pp. 144-149). Beijing: Foreign Language 
Teaching and Research Press.

Xu, G. (1989). China's English Teaching History - An Elaborate Education History. Foreign Language Teaching and Research, 2, 52-56.

Yin, S. (2005). Public speaking education: A crucial addition to the English curriculum of Chinese universities. CELEA Journal, 28(4), 3-15.

Zhang, D. (2009). Public Speaking and the Development of Language Competence. In L. Wang, \& P. Li (Eds.), English Public Speaking in Global Context: Challenges and Innovations (pp. 125-133). Beijing: Foreign Language Teaching and Research Press.

\section{Notes}

Note 1. Professor Ren Wen, Deputy Director of National Committee for Public Speaking and Debating in Foreign Languages, mentioned these two figures at the preparatory meeting of the National Committee for Public Speaking and Debating in Foreign Languages on December 9, 2011.

Note 2. CECR 2007 defines the objective of college English curriculum as "to develop students' ability to use English in a well-rounded way, especially in listening and speaking, so that in their future studies and careers as well as social interactions they will be able to communicate effectively, and at the same time enhance their ability to study independently and improve their general cultural awareness so as to meet the needs of China's social development and international exchanges".

Note 3. Yan Hui (521-481 BC), Confucius's favorite disciple.

Note 4. The limited space does not allow me to show more of their self-assessments. The two excerptions here are copied or translated from my students' original self-assessments with their permission but under pseudonyms to protect their privacy.

Note 5. The formative assessment refers to "all those activities undertaken by teachers, and/or by students, which provide information to be used as feedback to modify the teaching and learning activities in which they are engaged." (Black and Wiliam, 1998) Formative assessment is typically contrasted with summative assessment. The former supports teachers and students in decision-making during educational and learning processes, while the latter occurs at the end of a learning unit and determines if the content being taught was retained. (Ainsworth, 2006, p. 23)

Note 6 . With that in mind, we also attach great importance to students' attendance. It is made clear to students in the very beginning of the semester that regular and punctual attendance is vital, and excessive absences can result in a heavy penalty on their final grade. 